\title{
Article
}

\section{Clinical and Laboratory Characteristics of Kikuchi-Fujimoto Disease According to Age}

\author{
Hye-Young Kim ${ }^{1}$, Ha Young Jo ${ }^{2}$ and Seong Heon Kim ${ }^{3, *}$ \\ 1 Department of Pediatrics, Medical Research Institute, Pusan National University School of Medicine, Pusan \\ National University Hospital, Busan, Republic of Korea; pearlhy@naver.com \\ 2 Department of Pediatrics, Pusan National University Hospital, Busan, Republic of Korea; \\ gocaki_@naver.com \\ 3 Department of Pediatrics, Seoul National University Children's Hospital, Seoul, Republic of Korea; \\ pedksh@gmail.com \\ * Correspondence: pedksh@gmail.com; Tel.: +82-02-2072-4304
}

\begin{abstract}
Background: Little information exists regarding the differences in the clinical and laboratory characteristics of Kikuchi-Fujimoto disease (KFD) according to age. Objective: To evaluate the clinical and laboratory characteristics of KFD according to age. Methods: We retrospectively evaluated patients diagnosed with KFD at Pusan National University Hospital between 2010 and 2020. Results: Eighty patients (46 children and 34 adults) with a mean age of $21.5 \pm 11.8$ years (range, 3 49 years) were included in the study. Among children, the male sex ratio was higher, in adults, the female sex ratio was higher. Fever, tenderness in the lymph node, and skin rashes were more common in children, while myalgia and weight loss were more common in adults. In children, the recurrence rate was significantly higher among boys than among girls ( $15.8 \%$ vs $0.0 \%, \mathrm{P}=0.001)$. EBV and ANA positivity rates were higher in boys than in girls. In adults, the recurrence rate was significantly higher in women than in men $(18.2 \%$ vs $0.0 \%, P=0.005)$. ANA positivity rates were higher in women than in men. Conclusion: The clinical features, laboratory findings, and recurrence of KFD may differ depending on age and sex. Clinicians should be aware of this.
\end{abstract}

Keywords: Kikuchi-Fujimoto disease; histiocytic necrotizing lymphadenitis; prognosis; children; age

\section{Introduction}

Kikuchi-Fujimoto disease (KFD), also called Kikuchi disease or histiocytic necrotizing lymphadenitis, is known to be a rare, generally self-limiting condition of unknown cause, usually characterized by cervical lymphadenopathy, fever, and leukopenia.[1] As the symptoms are non-specific, differential diagnoses, including viral infections, malignancies, and autoimmune conditions such as systemic lupus erythematosus are often considered. The diagnosis of KFD is usually based on lymph node histology, which features variably confluent paracortical necrosis surrounded by a prominent collar of histiocytes with crescentic nuclei, immunoblasts, and plasmacytoid monocytes.

While the pathogenesis of Kikuchi disease is unknown, the clinical presentation, course, and histologic changes suggest an immune response of $\mathrm{T}$ cells and histiocytes to an infectious agent. Infectious agents, including Yersinia, Toxoplasma, Epstein-Barr virus, human herpes virus 6 and 8, human T-lymphotropic virus type 1, and parvovirus B19 have been reported to play a causative role, but this has not been confirmed.[2,3]

Although KFD affects all age and sex groups, the clinical features of KFD may differ according to age and sex. It was primarily thought to be a disease affecting women under the age of 30 years. However, in a Korean report of 20 individuals younger than 18 years of age with Kikuchi disease, the sex distribution is equal.[4] Others have suggested that, among children, boys are slightly more frequently affected than girls, in contrast to older 
patients.[5,6] In addition, KFD has a reported recurrence rate of 3-4\%,[7] but pediatric studies have shown a higher recurrence rate of up to $42.4 \%$.[8-10]

The age- and sex-related differences in KFD characteristics are not yet fully understood. Many KFD studies have focused on adults; thus, there is little information on the differences in the presentation of KFD according to age. Therefore, it is necessary to understand the differences in the clinical and laboratory features of KFD according to age and sex. We analyzed the clinical and laboratory characteristics of patients with KFD according to age and sex.

\section{Materials and Methods}

We reviewed the medical records of KFD patients who were diagnosed between January 2010 and September 2020 at Pusan National University Hospital. Our university hospital is a reference center for six million inhabitants in Busan and Gyeongnam, Korea. The study protocol was approved by the institutional review board of Pusan National University Hospital (PNUHIRB 2012-032-098). The diagnosis of KFD was made on the basis of histopathologic findings of affected lymph nodes obtained by fine needle aspiration (FNA) or excisional biopsy after exclusion of other diseases, such as multifocal necrosis in the paracortical area with karyorrhectic debris and various histiocytes with crescentic nuclei in the absence of neutrophils.[11-13]

Initially, FNA was performed in 68 patients, and excisional biopsy was performed in 12 patients. FNA cytology was used as a diagnostic test in 61 of 68 patients, and the remaining seven patients required additional excisional biopsy. The decision on the performance and timing of the histocytologic confirmation was made depending on the patient's condition and the severity and duration of their symptom manifestations. Clinical features, laboratory findings, courses, and follow-up results were collected and analyzed. Subjects under 19 years of age were defined as children, and those above or equal to 19 years of age were defined as adults. EBV positivity was defined when the EBV IgM viral capsid antigen (VCA) or EBV polymerase chain reaction (PCR) blood assays were positive.

Statistical analysis was performed using SPSS for Windows (version 21.0; SPSS, Chicago, IL, USA). The data are expressed as means \pm standard deviations or as percentages where appropriate. The clinical and demographic data were compared between groups using the chi-square analysis and the Mann-Whitney U test. P values $<0.05$ were considered statistically significant.

\section{Results}

A total of 80 patients ( 46 children and 34 adults) were included in the study. Twenty $(43.5 \%)$ children and $22(64.7 \%)$ adults were female, and the proportion of female patients was significantly higher among adults than among children ( $\mathrm{P}=0.003)$ (Table 1$)$. The mean age of the study subjects was $21.5 \pm 11.8$ years (range, $3-49$ years). The mean age was 13.2 \pm 4.8 years for children and $32.7 \pm 8.8$ years for adults. Among the 80 patients, the age distribution was as follows: 12 were $(15.0 \%)$ aged $\leq 9,34(42.5 \%)$ were aged $10-19,14$ $(17.5 \%)$ were aged $20-29,14(17.5 \%)$ were aged $30-39$, and $6(7.5 \%)$ were aged $\geq 40$ years. Those aged between 10-19 years accounted for the largest number of patients (42.5\%).

Table 1. Manifestations of Kikuchi-Fujimoto disease by age

\begin{tabular}{lllll}
\hline Characteristics & Total & Children & Adults & $P$-value \\
\hline Number of patients & 80 & 46 & 34 & \\
Sex (Male/Female) & $38 / 42$ & $26 / 20$ & $12 / 22$ & 0.003 \\
Age group (years) & $21.5 \pm 11.8$ & $13.2 \pm 4.8$ & $32.7 \pm 8.8$ & \\
$0-9$ & $12(15.0)$ & & & \\
$10-19$ & $34(42.5)$ & & & \\
$20-29$ & $14(17.5)$ & & & \\
\hline
\end{tabular}




\begin{tabular}{|c|c|c|c|c|}
\hline $30-39$ & $14(17.5)$ & & & \\
\hline$\geq 40$ & $6(7.5)$ & & & \\
\hline \multicolumn{5}{|l|}{ Symptoms } \\
\hline Fever & $52(65.0)$ & $34(73.9)$ & $18(52.9)$ & 0.005 \\
\hline Tender lymph node & $48(60.0)$ & $34(73.9)$ & $14(41.2)$ & 0.002 \\
\hline Myalgia & $16(20.0)$ & $6(13.0)$ & $10(29.4)$ & 0.013 \\
\hline Weight loss (>2 kg) & $10(12.5)$ & $4(8.7)$ & $6(17.6)$ & 0.012 \\
\hline Arthralgia & $8(10.0)$ & $4(8.7)$ & $4(11.8)$ & 0.062 \\
\hline Rash & $6(7.5)$ & $6(13.0)$ & $0(0.0)$ & 0.001 \\
\hline \multicolumn{5}{|l|}{ Lymphadenopathy } \\
\hline Cervical (\%) & $72(90.0)$ & $44(95.7)$ & $28(82.4)$ & 0.023 \\
\hline Unilateral (\%) & $44(55.0)$ & $26(56.5)$ & $18(52.9)$ & 0.121 \\
\hline Bilateral (\%) & $28(35.0)$ & $18(39.1)$ & $10(29.4)$ & 0.021 \\
\hline Generalized (\%) & $8(10.0)$ & $2(4.3)$ & $6(17.6)$ & 0.015 \\
\hline LN max. diameter $(\mathrm{cm})$ & $1.93 \pm 1.09$ & $2.35 \pm 0.57$ & $1.93 \pm 0.46$ & 0.078 \\
\hline Relapse & $8(10.0)$ & $4(8.7)$ & $4(11.8)$ & 0.107 \\
\hline \multicolumn{5}{|l|}{ Laboratory findings } \\
\hline WBC (/mm3) & $4234 \pm 1761$ & $4165 \pm 1366$ & $4333 \pm 2264$ & 0.214 \\
\hline $\mathrm{ANC}(/ \mathrm{mm} 3)$ & $2413 \pm 1475$ & $2110 \pm 1017$ & $2845 \pm 1916$ & 0.099 \\
\hline $\mathrm{Hb}(\mathrm{mg} / \mathrm{dL})$ & $12.8 \pm 3.7$ & $12.9 \pm 2.4$ & $12.7 \pm 4.1$ & 0.453 \\
\hline Platelet (/mm3) & $256 \pm 66$ & $266 \pm 71$ & $251 \pm 89$ & 0.667 \\
\hline LDH (IU/1) & $477 \pm 338$ & $509 \pm 340$ & $416 \pm 349$ & 0.327 \\
\hline AST (IU/l) & $49 \pm 41$ & $53 \pm 46$ & $42 \pm 33$ & 0.201 \\
\hline ALT (IU/l) & $40 \pm 58$ & $42 \pm 45$ & $37 \pm 74$ & 0.222 \\
\hline CRP (mg/dl) & $1.30 \pm 2.04$ & $0.93 \pm 0.98$ & $1.82 \pm 2.94$ & 0.078 \\
\hline ESR (mm/hr) & $34.8 \pm 23.4$ & $32.7 \pm 20.1$ & $37.1 \pm 26.4$ & 0.122 \\
\hline EBV positive, n/N (\%) & $8 / 48(16.7)$ & $8 / 28(28.5)$ & $0 / 20(0.0)$ & 0.001 \\
\hline ANA positive, n/N (\%) & $15 / 55(27.3)$ & $8 / 30(26.6)$ & $7 / 22(31.8)$ & 0.098 \\
\hline
\end{tabular}

$\mathrm{N}$ indicates the total number of patients who underwent the test.

Data are shown as mean \pm standard deviation or median with interquartile range or percentage. LN, lymph node; WBC, white blood cell; ANC, absolute neutrophil; $\mathrm{Hb}$, hemoglobin; $\mathrm{LDH}$, lactate dehydrogenase; AST, aspartate transaminase; ALT, alanine transaminase; CRP, C-reactive protein; ESR, erythrocyte sedimentation rate; EBV, Epstein-barr virus; ANA, anti-nuclear antibodies.

Fifty-two patients (65.0\%) had fever, and tender lymph nodes were observed in $60.0 \%$ of patients. Fever and tender lymph nodes were far more prevalent in children than in adults $(73.9 \%$ vs. $52.9 \%, \mathrm{P}=0.005 ; 73.9 \%$ vs $41.2 \%, \mathrm{P}=0.002$, respectively). Myalgia and weight loss ( $>2 \mathrm{~kg}$ ) occurred in $13.0 \%$ and $8.7 \%$ of the children and in $29.4 \%$ and $17.6 \%$ of the adults, respectively. These symptoms were significantly higher in adults than in children $(\mathrm{P}=0.013$ and $\mathrm{P}=0.012$, respectively). Although rash was not common, it was more common in children $(13.0 \%$ vs. $0 \%, \mathrm{P}=0.001)$. All patients presented with lymphadenopathy, with cervical nodes involved in 72 (90.0\%) patients, axillary nodes involved in 7 $(8.8 \%)$ patients, inguinal nodes involved in $5(6.3 \%)$, mesenteric nodes involved in 2 $(2.5 \%)$, and generalized lymphadenopathy involving two or more anatomic sites in eight $(10.0 \%)$ patients. While cervical lymphadenopathy, especially bilateral lymphadenopathy, was more common in children than in adults, generalized lymphadenopathy was more common in adults than in children (Table 1). There was no difference in lymph node size between the children and adults. There were four recurrence cases in children and adults. The rate of EBV positivity was higher in children than in adults $(28.5 \%$ vs. $0.0 \%, \mathrm{P}=0.001)$. The other laboratory findings, including WBC, Hb, platelet, AST ALT, CRP, ESR, and ANA positivity rates, were not different between the two groups (Table 1). 
In children, the male sex ratio was higher, especially for patients aged $\leq 9$ years (Table 2 ). Fever was more common in boys than in girls $(92.3 \%$ vs. $50.0 \%, \mathrm{P}=0.002)$. Bilateral cervical lymphadenopathy was observed more frequently in boys than in girls $(53.8 \%$ vs. $20.0 \%, \mathrm{P}=0.001)$. The recurrence rate was also significantly higher in boys than in girls. $(15.8 \%$ vs $0.0 \%, P=0.001)$. In boys, we found lower platelet counts and higher CRP levels than in girls. Furthermore, EBV and ANA positivity rates were higher in boys than in girls (Table 2).

Table 2. Manifestations of Kikuchi-Fujimoto disease in children by sex

\begin{tabular}{|c|c|c|c|c|}
\hline Characteristics & Total & Male & Female & $P$-value \\
\hline Number of patients (\%) & $46(100)$ & $26(56.5)$ & $20(43.5)$ & 0.038 \\
\hline Age (years) & $13.2 \pm 4.8$ & $11.46 \pm 5.17$ & $15.50 \pm 3.24$ & 0.002 \\
\hline \multicolumn{5}{|l|}{ Age group (years) } \\
\hline $0-9$ & & $10(26.3)$ & $2(4.8)$ & 0.001 \\
\hline 10-19 & & $16(42.1)$ & $18(42.9)$ & 0.612 \\
\hline \multicolumn{5}{|l|}{ Symptoms } \\
\hline Fever & $34(73.9)$ & $24(92.3)$ & $10(50.0)$ & 0.001 \\
\hline Tender lymph node & 34 (73.9) & $20(76.9)$ & $14(70.0)$ & 0.081 \\
\hline Weight loss (>2 kg) & $4(8.7)$ & $2(7.7)$ & $2(10.0)$ & 0.127 \\
\hline Arthralgia & $4(8.7)$ & $2(7.7)$ & $2(10.0)$ & 0.127 \\
\hline Rash & $6(13.0)$ & $3(11.5)$ & $3(15.0)$ & 0.091 \\
\hline \multicolumn{5}{|l|}{ Lymphadenopathy } \\
\hline Cervical (\%) & $44(95.7)$ & $24(92.3)$ & $18(90.0)$ & 0.211 \\
\hline Unilateral (\%) & $26(56.5)$ & $12(46.2)$ & $14(70.0)$ & 0.002 \\
\hline Bilateral (\%) & $18(39.1)$ & $14(53.8)$ & $4(20.0)$ & 0.002 \\
\hline Generalized (\%) & $2(4.3)$ & $1(1.4)$ & $1(5.0)$ & 0.081 \\
\hline LN max. diameter $(\mathrm{cm})$ & $2.35 \pm 0.57$ & $2.38 \pm 0.51$ & $2.30 \pm 0.67$ & 0.078 \\
\hline Relapse & $4(8.7)$ & $4(15.8)$ & $0(0.0)$ & 0.001 \\
\hline \multicolumn{5}{|l|}{ Laboratory findings } \\
\hline WBC (/mm3) & $4165 \pm 1366$ & $4482 \pm 1484$ & $3690 \pm 1083$ & 0.098 \\
\hline ANC $(/ \mathrm{mm} 3)$ & $2110 \pm 1017$ & $2137 \pm 1202$ & $2069 \pm 731$ & 0.199 \\
\hline $\mathrm{Hb}(\mathrm{mg} / \mathrm{dL})$ & $12.9 \pm 2.4$ & $13.1 \pm 9.3$ & $12.8 \pm 7.3$ & 0.285 \\
\hline Platelet (/mm3) & $266 \pm 71$ & $169 \pm 91$ & $299 \pm 93$ & 0.022 \\
\hline $\mathrm{LDH}(\mathrm{IU} / \mathrm{l})$ & $509 \pm 340$ & $602 \pm 407$ & $370 \pm 139$ & 0.061 \\
\hline AST (IU/l) & $53 \pm 46$ & $68 \pm 54$ & $32 \pm 13$ & 0.062 \\
\hline ALT (IU/l) & $42 \pm 45$ & $54 \pm 54$ & $23 \pm 11$ & 0.078 \\
\hline CRP $(\mathrm{mg} / \mathrm{dl})$ & $0.93 \pm 0.98$ & $1.31 \pm 1.13$ & $0.40 \pm 0.32$ & 0.032 \\
\hline EBV positive, n/N (\%) & $8 / 38(22.2)$ & $6 / 16(37.5)$ & $2 / 12(16.7)$ & 0.025 \\
\hline ANA positive, n/N (\%) & $7 / 30(26.6)$ & $6 / 20(30.0)$ & $1 / 10(10.0)$ & 0.021 \\
\hline
\end{tabular}

$\mathrm{N}$ indicates the total number of patients who underwent the test.

Data are shown as mean \pm standard deviation or median with interquartile range or percentage. LN, lymph node; WBC, white blood cell; ANC, absolute neutrophil; $\mathrm{Hb}$, hemoglobin; $\mathrm{LDH}$, lactate dehydrogenase; AST, aspartate transaminase; ALT, alanine transami-nase; CRP, C-reactive protein; EBV, Epstein-barr virus; ANA, anti-nuclear antibodies.

In adults, the female sex ratio was higher, especially for patients aged 20-29 years (Table 3). Tender lymph nodes were more common in women than in men $(54.5 \%$ vs $16.7 \%, \mathrm{P}=0.001)$. Unilateral cervical lymphadenopathy was observed more frequently in women than in men $(63.6 \%$ vs. $33.3 \%, \mathrm{P}=0.007)$. The recurrence rate was also significantly higher in women than in men ( $18.2 \%$ vs $0.0 \%, P=0.005)$. ANA positivity rates were higher in women than in men (Table 3). 
Table 3. Manifestations of Kikuchi-Fujimoto disease in adults by sex

\begin{tabular}{|c|c|c|c|c|}
\hline Characteristics & Total & Male & Female & $P$-value \\
\hline Number of patients (\%) & $34(100)$ & $12(35.3)$ & $22(64.7)$ & 0.018 \\
\hline Age (years) & $32.71 \pm 8.82$ & $32.50 \pm 8.02$ & $32.82 \pm 9.60$ & 0.459 \\
\hline \multicolumn{5}{|l|}{ Age group (years) } \\
\hline $20-29$ & $14(17.5)$ & $4(10.5)$ & $10(23.8)$ & 0.011 \\
\hline $30-39$ & $14(17.5)$ & $6(15.8)$ & $8(19.0)$ & 0.109 \\
\hline$>40$ & $6(7.5)$ & $2(5.3)$ & $4(9.5)$ & 0.187 \\
\hline \multicolumn{5}{|l|}{ Symptoms } \\
\hline Fever & $18(52.9)$ & $6(50.0)$ & $12(54.5)$ & 0.214 \\
\hline Tender lymph node & $14(41.2)$ & $2(16.7)$ & $12(54.5)$ & 0.001 \\
\hline Weight loss (>2 kg) & $6(17.6)$ & $2(16.7)$ & $4(18.2)$ & 0.127 \\
\hline Arthralgia & $4(11.8)$ & $1(8.4)$ & $3(13.6)$ & 0.127 \\
\hline Rash & $0(0.0)$ & $0(0.0)$ & $0(0.0)$ & 0.091 \\
\hline \multicolumn{5}{|l|}{ Lymphadenopathy } \\
\hline Cervical (\%) & $28(82.4)$ & $10(83.3)$ & $18(81.8)$ & 0.383 \\
\hline Unilateral (\%) & $18(52.9)$ & $4(33.3)$ & $14(63.6)$ & 0.007 \\
\hline Bilateral (\%) & $10(29.4)$ & $6(50.0)$ & $4(18.2)$ & 0.013 \\
\hline Generalized (\%) & $6(17.6)$ & $2(16.7)$ & $4(18.2)$ & 0.456 \\
\hline LN max. diameter $(\mathrm{cm})$ & $1.93 \pm 0.46$ & $1.40 \pm 0.45$ & $1.22 \pm 0.38$ & 0.203 \\
\hline Relapse & $4(11.8)$ & $0(0.0)$ & $4(18.2)$ & 0.005 \\
\hline \multicolumn{5}{|l|}{ Laboratory findings } \\
\hline WBC $(/ \mathrm{mm} 3)$ & $4333 \pm 2264$ & $4173 \pm 1348$ & $4453 \pm 2860$ & 0.521 \\
\hline $\mathrm{ANC}(/ \mathrm{mm} 3)$ & $2845 \pm 1916$ & $2745 \pm 1207$ & $2920 \pm 2401$ & 0.365 \\
\hline $\mathrm{Hb}(\mathrm{mg} / \mathrm{dL})$ & $12.7 \pm 3.1$ & $12.8 \pm 2.4$ & $12.6 \pm 3.4$ & 0.771 \\
\hline Platelet (/mm3) & $251 \pm 89$ & $270 \pm 86$ & $239 \pm 92$ & 0.214 \\
\hline $\mathrm{LDH}(\mathrm{IU} / \mathrm{l})$ & $416 \pm 349$ & $354 \pm 74$ & $454 \pm 453$ & 0.337 \\
\hline AST (IU/1) & $42 \pm 33$ & $40 \pm 22$ & $44 \pm 41$ & 0.451 \\
\hline ALT (IU/l) & $37 \pm 74$ & $20 \pm 7$ & $49 \pm 99$ & 0.468 \\
\hline CRP (mg/dl) & $1.82 \pm 2.94$ & $1.94 \pm 2.27$ & $1.72 \pm 3.52$ & 0.399 \\
\hline EBV positive $\mathrm{n} / \mathrm{N}(\%)$ & $0 / 10(0.0)$ & $0 / 3(0.0)$ & $0 / 7(0.0)$ & NA \\
\hline ANA positive, n/N (\%) & $7 / 16(43.7)$ & $2 / 6(33.3)$ & $5 / 10(50.0)$ & 0.037 \\
\hline
\end{tabular}

$\mathrm{N}$ indicates the total number of patients who underwent the test.

Data are shown as mean \pm standard deviation or median with interquartile range or percentage. LN, lymph node; WBC, white blood cell; ANC, absolute neutrophil; $\mathrm{Hb}$, hemoglobin; $\mathrm{LDH}$, lactate dehydrogenase; AST, aspartate transaminase; ALT, alanine transami-nase; CRP, C-reactive protein; EBV, Epstein-barr virus; NA, not available; ANA, anti-nuclear antibodies.

The clinical characteristics of the patients with Kikuchi disease recurrence are described in Table 4 . There were four children and four adults. All children were male, while all adults were female. The range of fever duration was 9-30 days. Two children were EBV-positive. ANA positive results were observed in two children and three adults. 
Table 4. Kikuchi-Fujimoto disease patients with relapse

\begin{tabular}{|c|c|c|c|c|c|c|c|c|c|}
\hline No & $\begin{array}{l}\text { Age } \\
\text { (years) }\end{array}$ & Gender & $\begin{array}{l}\text { Fever } \\
\text { duration } \\
\text { (days) }\end{array}$ & LN site & $\begin{array}{l}\text { LN } \\
\text { maximum } \\
\text { size }(\mathrm{cm})\end{array}$ & $\begin{array}{l}\text { EBV } \\
\text { positive }\end{array}$ & $\begin{array}{l}\text { ANA } \\
\text { positive }\end{array}$ & $\begin{array}{l}\text { No of } \\
\text { relapse }\end{array}$ & $\begin{array}{l}\text { Follow- } \\
\text { up dura- } \\
\text { tion } \\
\text { (years) }\end{array}$ \\
\hline 1 & 6 & M & 16 & $\begin{array}{l}\text { Unilateral C. } \\
\text { and involved } \\
\text { inguinal }\end{array}$ & 2.5 & + & - & 1 & 3 \\
\hline 2 & 7 & M & 14 & Unilateral C. & 1.5 & - & - & 1 & 2 \\
\hline 3 & 8 & M & 9 & Bilateral C. & 2.0 & - & + & 2 & 4 \\
\hline 4 & 8 & M & 14 & Unilateral C & 2.5 & + & + & 1 & 1 \\
\hline 5 & 29 & $\mathrm{~F}$ & 30 & $\begin{array}{l}\text { Unilateral C. } \\
\text { and Involved } \\
\text { axilla }\end{array}$ & 2.0 & - & + & 2 & 3 \\
\hline 6 & 32 & $\mathrm{~F}$ & 30 & Involved axilla & 1.5 & - & - & 1 & 2 \\
\hline 7 & 38 & F & 15 & $\begin{array}{l}\text { Unilateral C. } \\
\text { and Involved } \\
\text { axilla }\end{array}$ & 1.0 & - & + & 1 & 4 \\
\hline 8 & 47 & F & 20 & Bilateral C. & 2.0 & - & + & 3 & 6 \\
\hline
\end{tabular}

LN, lymph node;. EBV, Epstein-barr virus; ANA, anti-nuclear antibodies; C, cervical.

\section{Discussion}

KFD has a broad clinical spectrum, including fever and cervical lymphadenopathy, which are the most common symptoms. In our study, we investigated the clinical and laboratory characteristics and KFD according to age and sex. We found that there were some differences in clinical patterns with age. The prevalence of KFD is known to be higher in Asian and Eastern European populations. $[1,3,14]$ KFD usually occurs in the 30s and $40 \mathrm{~s}$, and has a female predominance with a ratio of $\sim 3-4: 1$ in young adults[15]; however, in children, there are inconsistent results in terms of sex differences, although it seems that female predominance, as seen in young adults, is not evident.[2,6,16-18] Moreover, some studies reported male predominance in children.[2,17,18] Kim et al. showed a male predominance under the age of 14 (1:1.6) and a female predominance over the age of 15 (3:1).[2] This difference may be related to race and the small number of pediatric patients in the studies. To the best of our knowledge, there have been few papers comparing adults and children in one institution and our study has the advantage of being performed under controlling the variables of race and region. We found male predominance among children and female predominance among adults in one institution, and these differences were statistically significant. Although the exact pathophysiology of KFD is still unknown, it may be assumed that there are different pathological mechanisms in children compared to those in adults. The youngest child was 3 years old, with a mean age of 13.2 years, similar to previous studies.[6,15,17]

We identified differences in symptoms and laboratory findings between children and adults. Fever, tenderness in the lymph node, and skin rashes were more common in children, while myalgia and weight loss were more common in adults, with more systemic inflammatory symptoms in children than in adults. Lymphadenopathy was less common in children. These results are almost consistent with those of previous studies by Kim et al.[2] Although it is not clear why there were more systemic symptoms in children, we suspect that differences in immune responses between children and adults, roles of sex hormones, and infection frequencies may play a role; however, further research is needed. In a study comparing clinical-cytological features in adults and children, children were significantly less likely to have high cellularity and Kikuchi histiocyte counts $>5 \%$ than adults.[19] 
Our study also showed that the positive rate of EBV, one of the trigger factors of KFD, was higher in children, particularly among boys compared in adults. Although ANA positivity was higher in women than in men, ANA positivity was higher in boys than in girls. ANA-positive findings in boys are suspected to be related to EBV infection rather than persistent autoimmunity. EBV during acute infection or reactivation phase could lead to formation of the ANA and ENA autoantibodies.[33] Although there were no patients with overt SLE during the study period, careful observation and follow-ups are required due to the fact that autoimmunity due to EBV infection could be related to the development of SLE.[34,35]

KFD is generally known to be a self-limiting local lymphadenopathy; however, pediatricians sometimes experience recurrent or refractory KFD in children. Although the recurrence rate of KFD is generally known to be around 3-4\%, it has a higher recurrence rate in children.[3,20,21] Yoo et al. in a multivariate analysis reported a $42 \%$ recurrence rate in 33 children with KFD; they suggested that a past history of systemic illnesses and a higher absolute lymphocyte count were risk factors associated with recurrent KFD.[9] This study may have shown a slightly higher rate of recurrence because it included patients who had relapsed before the KFD was confirmed. In our study, the total relapse rate was $10 \%$; interestingly, all relapsed patients were male in children, while all were female in the adult group. In a recent study of 98 children with KFD, there was a higher proportion of boys who had recurrent KFD, although this was not statistically significant.[6] We ruled out relapsed patients before the KFD was confirmed because we were not sure whether it was a definite symptom of KFD.

Most of the patients who relapsed also improved with the administration of 1-2 months of nonsteroidal anti-inflammatory drugs (NSAIDs) and/or oral corticosteroids. Patients with frequent recurrences are likely to suffer from side effects of corticosteroids; thus, they usually require the administration of steroid-sparing drugs instead of longterm use corticosteroids, as in other autoimmune diseases. In KFD, hydroxychloroquine is known to be effective and can be an alternative to corticosteroids because of its favorable effects and safety.[22-24]. Hydroxychloroquine, originally developed as an antimalarial drug, is commonly used in the treatment of rheumatic diseases such as systemic lupus erythematosus and dermatomyositis due to its immunomodulatory effects.[25-27] Hydroxychloroquine suppresses the production of proinflammatory cytokines produced by peripheral mononuclear cells in the blood, such as IFN $\gamma$, TNF $\alpha$ interleukin (IL)-1, and IL6 . 20, 28, 29. Impaired apoptosis of self-reactive effector T cells is an important mechanism for autoimmunity. Hydroxychloroquine can suppress autoimmunity by promoting apoptosis in effector T cells and inhibiting T cell antigen receptor signaling.[30,31] In KFD, hydroxychloroquine can be effective for resolution of fever and systemic symptoms by impairing the production of IFN- $\gamma \cdot[23,32]$.

This study has some limitations. First, this was a retrospective study with a relatively small number of patients in a single hospital. Second, this was not a cohort study, so we could not fully understand the patients' recent conditions. However, our findings that suggest evident differences in the clinical and laboratory characteristics of KFD according to age are encouraging. Ideally, our results aid in improving our understanding of KFD according to age and sex and are helpful for clinicians.

Funding: This research received no external funding

Institutional Review Board Statement: The study was conducted according to the guidelines of the Declaration of Helsinki, and approved by the Institutional Review Board of Pusan National University Hospital, Busan, Korea (11 January 2021;protocol code 2012-032-098).

Informed Consent Statement: We used an opt-out consent method, which was approved by Institutional Review Board of Pusan National University Hospital, Busan, Korea.

Conflicts of Interest: The authors declare no conflict of interest. 


\section{References}

1. Kucukardali, Y.; Solmazgul, E.; Kunter, E.; Oncul, O.; Yildirim, S.; Kaplan, M. Kikuchi-Fujimoto Disease: analysis of 244 cases. Clin Rheumatol 2007, 26, 50-4, doi: 10.1007/s10067-006-0230-5.

2. Kim, T. Y.; Ha, K. S.; Kim, Y.; Lee, J.; Lee, K.; Lee, J. Characteristics of Kikuchi-Fujimoto disease in children compared with adults. Eur J Pediatr 2014, 173, 111-6, doi: 10.1007/s00431-013-2131-3.

3. Bosch, X.; Guilabert, A.; Miquel, R.; Campo, E. Enigmatic Kikuchi-Fujimoto disease: a comprehensive review. Am J Clin Pathol 2004, 122, 141-52, doi: 10.1309/YF08-1L4T-KYWV-YVPQ.

4. Seo, J. H.; Shim, H. S.; Park, J. J.; Jeon, S. Y.; Kim, J. P.; Ahn, S. K.; Hur, D. G.; Ahn, S. Y.; Kwon, O. J. A clinical study of histiocytic necrotizing lymphadenitis (Kikuchi's disease) in children. Int J Pediatr Otorhinolaryngol 2008, 72, 1637-42, doi: 10.1016/j.ijporl.2008.07.019.

5. Batton, E.; Alali, M.; Hageman, J. R.; Parilla, M.; Yu, K. O. A. Kikuchi-Fujimoto Disease in Children: An Important Diagnostic Consideration for Cervical Lymphadenitis. Pediatr Ann 2019, 48, e406-e411, doi: 10.3928/19382359-20190920-01.

6. Selvanathan, S. N.; Suhumaran, S.; Sahu, V. K.; Chong, C. Y.; Tan, N. W. H.; Thoon, K. C. Kikuchi-Fujimoto disease in children. J Paediatr Child Health 2020, 56, 389-393, doi: 10.1111/jpc.14628.

7. Hutchinson, C. B.; Wang, E. Kikuchi-Fujimoto disease. Arch Pathol Lab Med 2010, 134, 289-93, doi: 10.5858/134.2.289.

8. Kang, H. M.; Kim, J. Y.; Choi, E. H.; Lee, H. J.; Yun, K. W.; Lee, H. Clinical Characteristics of Severe Histiocytic Necrotizing Lymphadenitis (Kikuchi-Fujimoto Disease) in Children. J Pediatr 2016, 171, 208-12.e1, doi: 10.1016/j.jpeds.2015.12.064.

9. Yoo, I. H.; Na, H.; Bae, E. Y.; Han, S. B.; Lee, S. Y.; Jeong, D. C.; Kang, J. H. Recurrent lymphadenopathy in children with KikuchiFujimoto disease. Eur J Pediatr 2014, 173, 1193-9, doi: 10.1007/s00431-014-2306-6.

10. Park, H. S.; Sung, M. J.; Park, S. E.; Lim, Y. T. Kikuchi-Fujimoto disease of 16 children in a single center of Korea. Pediatr Allergy Immunol 2007, 18, 174-8, doi: 10.1111/j.1399-3038.2006.00505.x.

11. Dorfman, R. F.; Berry, G. J. Kikuchi's histiocytic necrotizing lymphadenitis: an analysis of 108 cases with emphasis on differential diagnosis. Semin Diagn Pathol 1988, 5, 329-45.

12. Kuo, T. T. Kikuchi's disease (histiocytic necrotizing lymphadenitis). A clinicopathologic study of 79 cases with an analysis of histologic subtypes, immunohistology, and DNA ploidy. Am J Surg Pathol 1995, 19, 798-809, doi: 10.1097/00000478-19950700000008.

13. Pileri, S.; Kikuchi, M.; Helbron, D.; Lennert, K. Histiocytic necrotizing lymphadenitis without granulocytic infiltration. Virchows Arch A Pathol Anat Histol 1982, 395, 257-71, doi: 10.1007/BF00429352.

14. Bosch, X.; Guilabert, A. Kikuchi-Fujimoto disease. Orphanet J Rare Dis 2006, 1, 18, doi: 10.1186/1750-1172-1-18.

15. Lin, H. C.; Su, C. Y.; Huang, S. C. Kikuchi's disease in Asian children. Pediatrics 2005, 115, e92-6, doi: 10.1542/peds.2004-0924.

16. Adhikari, R. C.; Sayami, G.; Lee, M. C.; Basnet, R. B.; Shrestha, P. K.; Shrestha, H. G. Kikuchi-Fujimoto disease in Nepal: a study of 6 cases. Arch Pathol Lab Med 2003, 127, 1345-8.

17. Lee, K. Y.; Yeon, Y. H.; Lee, B. C. Kikuchi-Fujimoto disease with prolonged fever in children. Pediatrics 2004, 114, e752-6, doi: 10.1542/peds.2004-0485.

18. Zou, C. C.; Zhao, Z. Y.; Liang, L. Childhood Kikuchi-Fujimoto disease. Indian J Pediatr 2009, 76, 959-62, doi: 10.1007/s12098-0090194-y.

19. Das, D. K.; Haji, B. I.; Al-Boijan, R. A.; Sheikh, Z. A.; Pathan, S. K.; Mannan, A. A. Kikuchi-Fujimoto disease in fine needle aspiration smears: a clinico-cytologic study of 18 pediatric cases and correlation with 68 adult patients. Indian J Pathol Microbiol 2012, 55, 333-8, doi: 10.4103/0377-4929.101739.

20. Han, H. J.; Lim, G. Y.; Yeo, D. M.; Chung, N. G. Kikuchi's disease in children: clinical manifestations and imaging features. J Korean Med Sci 2009, 24, 1105-9, doi: 10.3346/jkms.2009.24.6.1105.

21. Wang, T. J.; Yang, Y. H.; Lin, Y. T.; Chiang, B. L. Kikuchi-Fujimoto disease in children: clinical features and disease course. J Microbiol Immunol Infect 2004, 37, 219-24.

22. Chen, P. H.; Huang, Y. F.; Tang, C. W.; Wann, S. R.; Chang, H. T. Kikuchi-Fujimoto disease: an amazing response to hydroxychloroquine. Eur J Pediatr 2010, 169, 1557-9, doi: 10.1007/s00431-010-1256-x.

23. Lin, Y. C.; Huang, H. H.; Nong, B. R.; Liu, P. Y.; Chen, Y. Y.; Huang, Y. F.; Chiou, Y. H.; Lee, H. S. Pediatric Kikuchi-Fujimoto disease: A clinicopathologic study and the therapeutic effects of hydroxychloroquine. J Microbiol Immunol Infect 2019, 52, 395401, doi: 10.1016/j.jmii.2017.08.023.

24. Hyun, M.; So, I. T.; Kim, H. A.; Jung, H.; Ryu, S. Y. Recurrent Kikuchi's Disease Treated by Hydroxychloroquine. Infect Chemother 2016, 48, 127-31, doi: 10.3947/ic.2016.48.2.127.

25. Canadian Hydroxychloroquine Study Group. A randomized study of the effect of withdrawing hydroxychloroquine sulfate in systemic lupus erythematosus. N Engl J Med 1991, 324, 150-4, doi: 10.1056/NEJM199101173240303.

26. Dos Reis Neto, E. T.; Kakehasi, A. M.; de Medeiros Pinheiro, M.; Ferreira, G. A.; Marques, C. D. L.; da Mota, L. M. H.; Dos Santos Paiva, E.; Pileggi, G. C. S.; Sato, E. I.; Reis, A.; et al. Revisiting hydroxychloroquine and chloroquine for patients with chronic immunity-mediated inflammatory rheumatic diseases. Adv Rheumatol 2020, 60, 32, doi: 10.1186/s42358-020-00134-8.

27. Danza, Á.; Graña, D.; Goñi, M.; Vargas, A.; Ruiz-Irastorza, G. Hydroxychloroquine for autoimmune diseases. Rev Med Chil 2016, 144, 232-40, doi: 10.4067/S0034-98872016000200012.

28. Barrera, P.; Boerbooms, A. M.; van de Putte, L. B.; van der Meer, J. W. Effects of antirheumatic agents on cytokines. Semin Arthritis Rheum 1996, 25, 234-53, doi: 10.1016/s0049-0172(96)80035-7. 
29. Nirk, E. L.; Reggiori, F.; Mauthe, M. Hydroxychloroquine in rheumatic autoimmune disorders and beyond. EMBO Mol Med 2020, 12, e12476, doi: 10.15252/emmm.202012476.

30. Goldman, F. D.; Gilman, A. L.; Hollenback, C.; Kato, R. M.; Premack, B. A.; Rawlings, D. J. Hydroxychloroquine inhibits calcium signals in T cells: a new mechanism to explain its immunomodulatory properties. Blood 2000, 95, 3460-6.

31. van Loosdregt, J.; Spreafico, R.; Rossetti, M.; Prakken, B. J.; Lotz, M.; Albani, S. Hydroxychloroquine preferentially induces apoptosis of CD45RO+ effector T cells by inhibiting autophagy: a possible mechanism for therapeutic modulation of $\mathrm{T}$ cells. $J$ Allergy Clin Immunol 2013, 131, 1443-6.e1, doi: 10.1016/j.jaci.2013.02.026.

32. Sacre, K.; Criswell, L. A.; McCune, J. M. Hydroxychloroquine is associated with impaired interferon-alpha and tumor necrosis factor-alpha production by plasmacytoid dendritic cells in systemic lupus erythematosus. Arthritis Res Ther 2012, 14, R155, doi: 10.1186/ar3895.

33. Cuomo, L.; Cirone, M.; Di Gregorio, A. O.; Vitillo, M.; Cattivelli, M.; Magliocca, V.; Maiorano, S.; Meledandri, M.; Scagnolari, C.; La Rocca, S.; et al. Elevated antinuclear antibodies and altered anti-Epstein-Barr virus immune responses. Virus Res 2015, 195, 95-9, doi: 10.1016/j.virusres.2014.09.014.

34. Harley, J. B.; James, J. A. Epstein-Barr virus infection induces lupus autoimmunity. Bull NYU Hosp Jt Dis 2006, 64, 45-50.

35. James, J. A.; Robertson, J. M. Lupus and Epstein-Barr. Curr Opin Rheumatol 2012, 24, 383-8, doi: 10.1097/BOR.0b013e3283535801. 